\title{
Por um modelo de Formulação de políticas de saúde baseado no enfoque estratégico da planificação.
}

*Pesquisador assistente do Dept" de Administração e Planejamento em Saúde da ENSPIFIOCRUZ.

\section{Francisco Javier Uribe Rivera *}

$O$ artigo desenvolve, inicialmente, uma análise das premissas teóricas do planejamento estratégico, em contraposiçāo à lógica do enfoque normativo do planejamento. Em um segundo momento, o autor discute um modelo de formulação de politicas de saúde, baseado nas premissas do enfoque estratégico.

\section{1. - INTRODUÇĀO}

Escrevemos estas linhas com a intenção de discutir os principais elementos de um modelo de formulação de políticas de saúde, baseado no enfoque estratégico da planificação. Antes de entrar na modelística propriamente dita, faremos algumas considerações sobre as premissas gerais da planificação e sobre as características diferenciais da planificação nomativa e estratégica, que nos parece ajudarão à compreensão de tal modelo.

A nossa análise é uma tentativa de sintetização das abordagens de vários autores e de vários documentos, prin. cipalizando a produção do Prof. Carlos Matus, considerado um dos mais consistentes ideólogos da planificação estratégica na América Latina (no campo da planificação econô. mico-social) e o modelo de Formulação de Políticas de Saúde, elaborado pelo Centro Panamericano de Planificação em Saúde, junto com a OPS e publicado em 1975.

A finalidade do presente texto é de caráter eminente. mente didático e se liga a um projeto, de maior alcance, de produção de instrumentos didáticos para a aprendizagem dos alunos dos diferentes cursos de Planejamento de Saúde.

\section{2. - PLANEJAMENTO NORMATIVO/ESTRATËGICO}

O enfoque estratégico da Planificação em Saúde (que surge no final da década de 70 ) representa um questionamento profundo, conquanto não global, da lógica do enfoque normativo, consubstanciada no modelo CENDES/OPS de Programação em Saúde (1965). É um questionamento de caráter parcial ou não global (no sentido da ruptura) porque o enfoque estratégico não implica no abandono total do instrumental do CENDES (ainda válido na etapa programática), mas na recolocação ou reinserção desse instrumen. tal no interior de uma concepção e de um estilo qualitativamente diferente de planificação, realmente pertinentes a uma forma de desenvolvimento característico de nossas formações sociais subdesenvolvidas e de capitalismo dependente.

Mais do que um questionamento do instrumental téc. nico-programático, este questionamento se refere a um esti. 
lo ou a um enfoque que demonstrou ter pouca validade em situações caracterizadas como de pouca homogeneidade ao nivel do Poder e de baixa legitimidade popular. Na realidade o planejamento normativo parece confinado àquelas experiências em que existe uma boa concentração de poder (não há heterogeneidade de forças disputando no âmago do Poder) e um razoável consenso popular (social), garantindo o cumprimento das diretrizes e das normas do Plano. Isto é, às experiências que resolveram a questão da viabilidade pois que eliminaram os conflitos ou as contradições. A rigor, tal hipótese parece bastante distante, o que sugere que a onipresença da divisão e do partilhamento do poder social está a exigir o uso de um enfoque de planificação que assuma o conflito como um elemento central na construção dos Planos.

$\mathrm{O}$ que se questiona no enfoque normativo é o seu re. ducionismo economicista; é aquela formação de definição dos objetivos e dos meios ou das alternativas para alcançálos, exclusivamente baseada no custo/benefício econômico. Esta redutividade do planejamento à dimensão da normatividade econômica significa abandonar o princípio da totalidade que caracteriza a realidade histórica e que deve informar à planificação. De acordo com esse princípio a realida. de histórica não admite uma diferenciação entre os fatos políticos, econômicos, ideológicos, etc. Equivale a dizer que todos os fatos políticos são também fatos econômicos e vice-versa. Não se justificando a segregação da realidade em dimensões estanques, da mesma forma não se explica que o planejamento opere exclusivamente com categorias que respondam a essas dimensões parciais.

O grande desafio da planificação consiste na formula. ção de categorias ou de instrumentos que tenham uma razoável coerência ou consistência com essa realidade, ou seja, de categorias que permitam apreender as situaçōes globais que caracterizam a realidade.histórica. a Planificação, nesse entendimento, deve obedecer ao princípio da correspondência analítica.

Ao admitirmos, como decorrência dos princípios anteriores, que a planificação deva contemplar categorias de natureza político-social, junto com as econômicas, poderemos concluir que a planificação é um tipo de normatividade que não se encerra no âmbito exclusivamente quantitativo, como ocorre com a concepção normativa; ao contrário, a normatividade que a planificação pretende instituir deve ser construída a partir de elementos de qualidade, que correspondam ao âmbito da viabilidade politica das proposições normativas. A norma quantitativa para ser real precisa ser viável e esta viabilidade depende da dinâmica política e social que não se reduz a fórmulas econométricas. A quanti- 
ficação normativa e a análise de viabilidade são os dois elementos indissociáveis de um mesmo processo real. Tal interdependência dinâmica caracteriza o princípio da quantificação operativa.

Critica-se a rigidez ou a inflexibilidade do planejamento normativo, que não admite a revisão das normas (metas e/ou instrumentos). Esta rigidez está relacionada com o princípio do equilibrio (ou com uma particular interpretação de tal princípio). A norma é definida como a situação de equilíbrio terminal, de máxima racionalidade (noção de otimização) que se pretende impor à realidade. É por assim dizê-lo, o preenchimento cabal da incompletude observada na situação diagnóstica. Dentro de tal visão a norma se superpõe ao comportamento histórico e o enquadra segundo os requisitos do equilibrio. Este verdadeiro voluntarismo normativo está fundamentado na hipótese da possibilidade de controlar ou de domesticar a realidade histórica que tem uma racionalidade material, através da planificação - enquanto racionalidade formal. Está fundamentado, todavia, na hipótese da separabilidade daquelas duas racionalidades.

Mesmo admitindo o princípio inerente à Planificação, da racionalidade formal poder influenciar ou controlar a racionalidade material, não se pode deixar de criticar a visão estanque que exclui totalmente o sujeito da planificação da racionalidade material, assignando-lhe uma autonomia absoluta na interpretação e na atuação sobre o real (e um primado sobre tal realidade).

O critério de viabilidade enquanto o outro lado da quantificação normativa, obriga-nos a proceder à definição normativa a partir da análise do comportamento histórico. A norma deve proceder ou surgir do comportamento histórico, da história real, da sucessão de conflitos e contra. dições que a caracterizam e não representar um artifício que se busca concretizar a qualquer preço.

A norma enquanto possibilidade de equilibrio surge do desequilibrio, alimenta-se dinamicamente de desequilibrios e provoca novos desequilibrios. Ela não tem a capacidade de gerar equilibrios terminais, mas equilíbrios parciais, transitórios e dinâmicos. O princípio do equilibrio representa, nesta nova conceitualização, a busca de um equilibrio dinâmico e contraditório entre o comportamen to histórico e a norma. ${ }^{1}$

Feitas estas considerações de ordem epistemológica, sobre a Planificação e seus enfoques, procederemos a sistematizar rapidamente as diferenças entre o enfoque normativo c cstratégico. Matus em seu livro Política e Plano, ${ }^{2}$ ilustra estas diferenças da seguinte forma: 


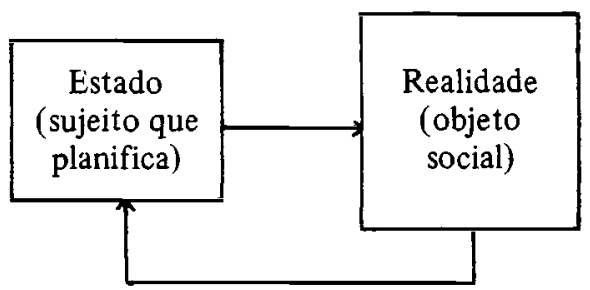

(1) ilustração lógica

do enfoque normativo

\section{Características do enfoque normativo}

- a planificação supõe um objeto e um sujeito independentes; o sujeito está colocado fora e acima da realidade, que é um sistema controlável;

- a planificação procura conhecer a realidade através do diagnóstico; orienta-se pela busca da verdade objetiva, científica; só há um único diagnóstico;

- a realidade apresenta comportamentos sociais estáveis e previsíveis, passíveis de serem estudados através de modelos analíticos ou de causalidade das Ciências Naturais e Biológicas (realidade objetiva).

- como a planificação admite um único ator e a realida. de é objetiva, a única normatividade possivel é a eco. nômica; o político é um dado exógeno ou uma mera restrição;

- o enfoque normativo trabalha com sistemas de final fechado (única chegada e única trajetória).

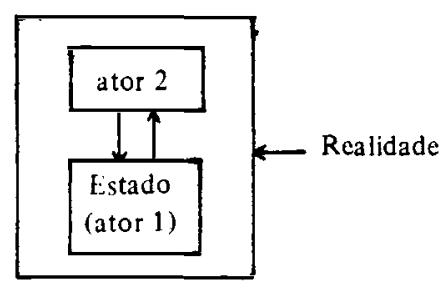

(2) Ilustraçāo do enfoque estratégico

\section{Características do enfoque estratégico}

- o sujeito que planifica está dentro da realidade (histó. rica) e coexistente com outros atores;

- há diferentes explicações, situações ou diagnósticos condicionados pelo lugar que os atores ocupam nessa realidade;

- a realidade não é objetual, não se.reduz à existência de comportamentos sociais estáveis; a "conduta" social não é previsível através de modelos analíticos das Ciências Tradicionais; é um processo criativo, 
pouco estruturado; a previsão supõe um cálculo estratégico interativo que admite várias probabilidadesde conduta ( simulação humana);

- a normalidade econômica não é a única; a viabilida. de politica define o "pode ser" de norma ou "deve ser" (direcionalidade); é um elemento endôgeno ao Plano;

- o enfoque estratégico trabalha com sistemas de final aberto (probabilísticos).

\section{3. - UM MODELO DE FORMULAÇÃO DE POLITIICAS DE SAÚDE}

Usamos como modelo básico de formulação de políticas de saúde e modelo proposto pelo CPPS/OPS, em $1975^{3}$ ("Formulacion de Políticas de Salud" cap. III). Parece-nos que este modelo é altamente didático e permite a compreensão das diferentes etapas ou das operações mentais que fazem parte do desenho de uma política.

Este esquema, no entanto, deve ser questionado, revisado e enriquecido pelas contribuiçōes ulteriores de maneira a proporcionar um resultado mais dinâmico e mais atualizado. Dois questionamentos devem ser salientados: em primeiro lugar, o documento original trata as diferentes etapas ou formas de análise de maneira extremamente estanque, o que não se justifica, tendo em vista que o processo é iterativo, com as várias fases a contecendo repetida e simultaneamente a se imbricando mutuamente (ex. factibilidade e viabilidade; coerência e viabilidade); em segundo lugar, o documento do CPPS assume que o único ator facultado a elaborar uma imagem objetivo é a autoridade política, o que constitui um equívoco ou uma parcialização, jâ que todos os atores políticos e sociais têm essa capacidade.

O modelo básico em pauta consta das seguintes etapas e/ou operações (vide Fig.)

- A Formulação de uma Imagem-Objetivo (1 O), de natureza político-ideológica e alicerçada "tecnicamente" (no plano secundário) no diagnóstico de situação;

- A comparação entre a IO e a Situação Inicial (Si), identificando na Si as falhas, as carências, as lacunas, os obstáculos que se opõem ao cumprimento da IO (a Si é o "negativo" da IO); é a identificação da brecha ou do hiato existente entre Si e I.o, que deverá ser superada com as políticas e uma estratégia ("o como fazer" das políticas);

- A definição dos projetos preliminares (proposições ou políticas) a partir da identificação dos problemas prioritários de $\mathrm{Si}$ e das soluções prioritárias. Prioriza. 
ção segundo critérios e fundamentalmente políticos;

- as análises de Factibilidade e de Coerência de tais projetos. Retroalimentação. Criação Dinâmica de Factibilidade e de Coerência;

- A análise de Viabilidade. Retroalimentação. Criação Dinâmica de Viabilidade;

- A definição de uma Estratégia ou de um conjunto de projetos definitivos (programa direcional/arco direcio. nal) e de sua trajetória ou sequêencia real (arco estratégico);

- Formalização e Implementaçẫo;

Fig.: modelo Formulação

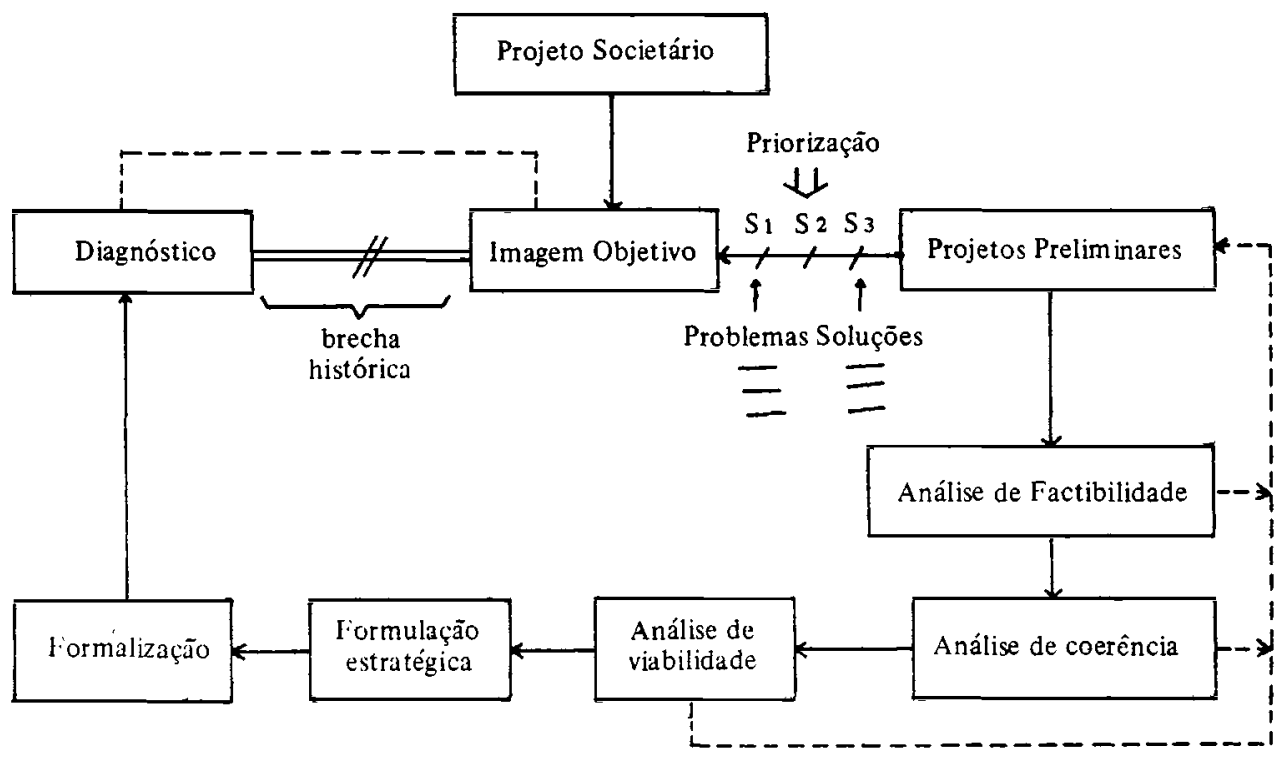

feed-back

\section{1 - A Formulação de uma 1.0 e a questão diagnóstica}

A I. O representa uma situação futura ideal ou desejada, que não está condicionada pela disponibilidade presente de recursos nem por prazos ou tempos determinados. A I. o se localiza na periferia do futuro concebível, em certo lugar do futuro. Corresponde a uma meta ativa, a ser buscada mediante a atuação consciente e planejada (diferente de uma meta espontânea). Refere-se tanto à situação de saúde quanto à estrutura $e$ ao funcionamento dos Serviços de Saúde (sendo que esta última é a mais importante, porque mais real e conflitiva). 
- diferentes das categorias de 20 e 3. grau, quantitativas, econômicas (ex. crescimento da renda em $\%$, como meta finalística). As categorias de $1^{O}$ grau se referem iqueles projetos de mudança, que, assumindo a forma de metas ou de situaçōes objetivos, expressam um projeto qualitativo de sociedade.
Os elementos que contribuem para a formulação da Imagem-Objetivo são os elementos ensejados pelo diagnóstico situacional (do prognóstico situacional) e primordialmente os valores políticos e ideológicos correspondentes em última instância ao projeto societário da força social que a contrói (sendo que todas as forças sociais podem desenhar uma l.o e pugnar por ela).

Exemplo de Imagem Objetivo: Sistema Único de Saúde, que obedeça aos princípios de cobertura universal, de equiidade, de descentralização, de integraçāo e de cogestão (I. o da Reforma Sanitária Brasileira).

Como a 1.0 se situa em certo lugar impreciso, longi: quo, do futuro, é necessário desdobrar tal I.o em situações intermediárias ou objetivos intermediários/S1, S2, S3,..), que definirão os momentos ou prazos determinados das políticas ou dos projetos a serem implementados tendo em vista a aproximação dinâmica e sucessiva da I.o.

A I.o deve cumprir alguns requisitos:

- representatividade: deve expressar as aspirações de grupos sociais realmente representativos e responder a problemas verdadeiros e transcendentais para eles;

- validade: resulta das sucessivas aproximações entre a imagem-preliminar (modelagem da I.o) e a viabilidade da trajetória, para evitar deste modo que possa ter um caráter utópico (a I.o definitiva, após revisão ou "modelagem" é aquela capaz de gerar ou de mobilizar uma estratégia viável).

- singularidade: sua elaboração e posterior coerência $\mathrm{com}$ os projetos sociais básicos da estratégia exige que ela seja precisada em termos de "abstrações de primeiro grau", isto é, de categorias qualitativas que representam de maneira singular um determinado padrão ou estilo de desenvolvimento $\left({ }^{*}\right)$.

- direcionalidade: a I.o define a direção do processo de desenvolvimento. E o deve ser ou a norma ideal que se pretende alcançar no futuro.

- capacidade semiótica: deve expressar em poucos símbolos genéricos a gama dos problemas e soluções que se busca equacionar. ${ }^{4}$

A definição da I.o representa o ponto de partida da formulaçâo política, na medida em que o próprio diagnóstico de situação é delineado em função dos interesses da 1.0 (diagnóstico intencional ou dirigido). Isto é, procuraremos extrair do diagnóstico os elementos funcionais com o cum. primento da I.o Por ex.: Se a l.o é a unificação racionalizadora do sistema de serviços de saúde (SUS), os elementos 
diagnósticos mais importantes se referem à estrutura da oferta, à explicação e descrição das caracteristicas de desintegração, de atomização dos S. S. de baixa cobertura (superposiçẫo de), de centralização, pouca participação, etc.

A comparação entre a l.o e o Diagnóstico de Si define a brecha histórica que terá que ser preenchida (superada) e que corresponde ao conjunto de mudanças parciais ou ao projeto global de mudança situacional que o planejamento pretende instituir.

A explicação situacional deve ser realizada, conseqüentemente, tendo em vista fornecer elementos para a mudança situacional. Ela deve ajudar a discriminar os niveis da realidade sobre os quais será necessário atuar para avançar na modificação sistêmica. E aqui é importante a contribuição do enfoque estratégico no que diz respeito à incorpora. ção na explicação diagnóstica da análise dos fatores condicionantes e determinantes dos fenômenos setoriais (sanitários), análise que permite ter uma visão de conjunto, "situacional", dos problemas específicos. Esta contribuição é uma forma de superação do enfoque normativo que diagnostica as características do epi (fenômeno) setorial, abstraindo a causalidade mais de fundo, relacionada com a lógica do poder e da formação social.

Para o enfoque estratégico moderno, a problematiza. ção do real deve ser feita em função dos vários níveis que, de maneira inter-relacionada, compōem a realidade, quais sejam:

- nível 1 do fenômeno: nível setorial onde o observável é a produção (fluxo de) de fatos específicos (de saúde). Ex.: n? de consultas, vacinaçōes, n? de óbitos, de altas, produtividade, cobertura, etc;

- nivel 2 da fenoestrutura: atuação política organizada a nível do Estado e da Soc. Civil - plano das organizações sociais em geral (políticas, econômicas, ideológicas), que têm a capacidade ou a faculdade de acumular/desacumular poder condicionando o alcance e a direção dos fatos que se produzem ao nível fenomênico (capacidade de produçâo de fatos) - nível setorial e global;

- nível 3 da genoestrutura: genética do sistema ou conjunto das leis básicas que regulam uma determinada formação social condicionando definitivamente os dois níveis anteriores - corresponde ao (s) conceito (s) operacional (is) de modo de produção, formação social, caráter geral do Estado, etc. ${ }^{5}$

Esta forma de estudar a realidade está ditada, repetimos, pela necessidade de distinguir os elementos (do poder 
e da formação social) que extrapolando o plano setorial condicionam "a variedade possível" dos fenômenos seto. riais e a possibilidade de se obter determinadas mudanças setoriais.

A necessidade de atuação sobre os níveis 2 e 3 da realidade impõe à planificação objetivos que transcendem a mera busca do aumento da produtividade, (que supõe um tipo de diagnóstico exclusivamente administrativo) e que passam a ter o significado de processos de mudança e de le. gitimação. A meta da mudança obriga quase que necessariamente à realização de diagnósticos do tipo estratégico, das categorias de poder setorial (vide o diagnóstico estratégico de Mário Testa) ${ }^{6}$.

O método ideal de análise do (s) problema (s) de saú. de pode ser o do fluxograma situacional, que consiste em inquirir sobre as causas ou processos condicionantes dos fatos diagnósticos, em uma cadeia explicativa seqüencial e sistemática que vai até as causas mais gerais ou básicas (passando pelos 3 níveis da realidade mencionados). Esse fluxograma deverá dar conta das múltiplas relações que se estabele. cem entre os fatos diagnosticados e entre os processos condicionantes (em todos os sentidos).

Ex.: Simplificação de uma problematização do fenômeno da baixa cobertura sanitária.

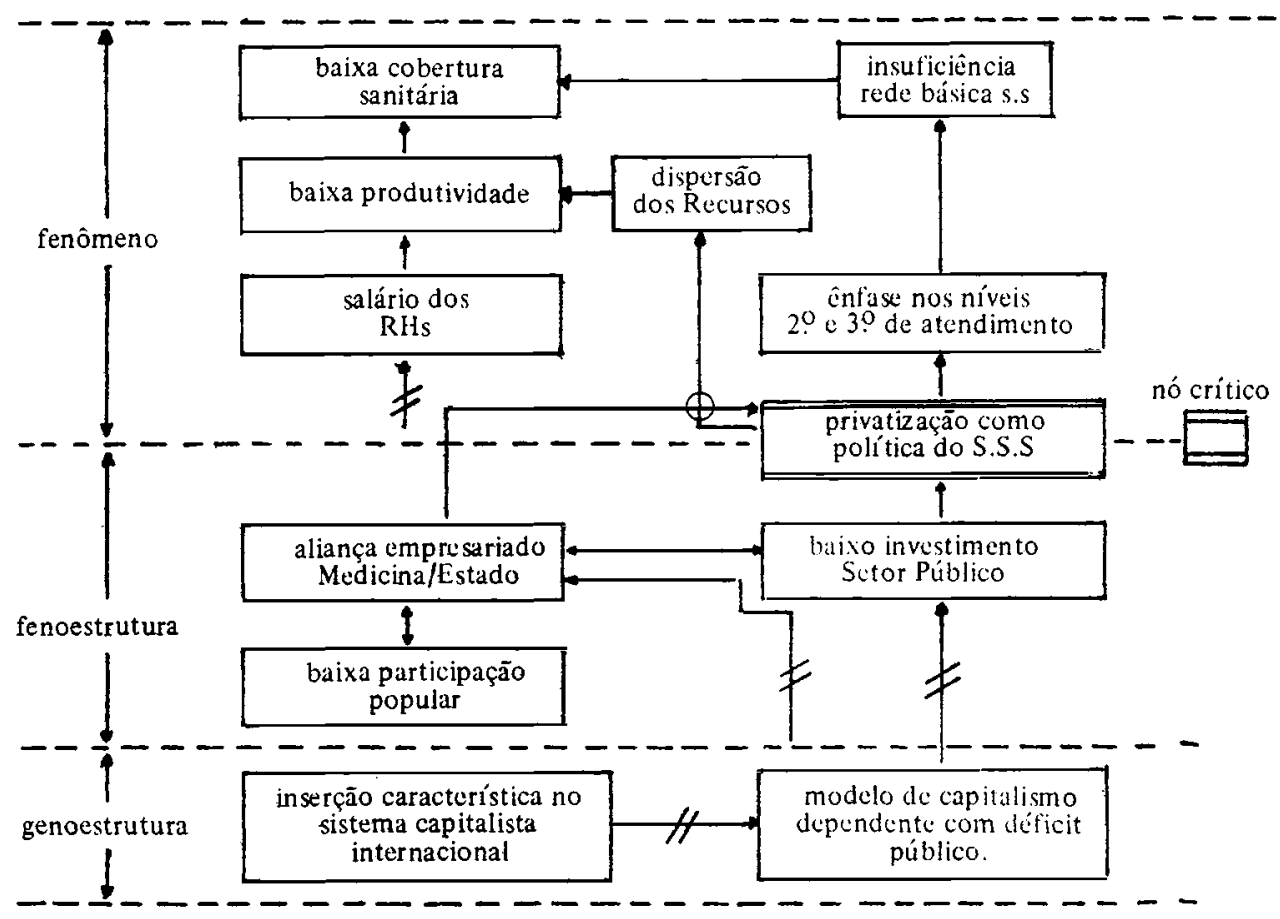


$\mathrm{O}$ passo seguinte à simulação da explicação situacional consiste na escolha daqueles nós explicativos (processos de casualidade) que apresentam uma maior sensibilidade de mudança, isto é, aqueles nós que, ao mudarem suas características, poderão determinar ou condicionar com maior intensidade relativas mudanças (no sentido da ampliação ou da eliminação) ao nível dos problemas anteriores na cadeia explicativa (pregressa). Esses nós explicativos passam a ser considerados nós críticos, ou pontos (privilegiados) de aplicação das estratégias de combate ${ }^{6}$.

O importante é avaliar em que medida as mudanças fenomênicas podem depender de uma atuação sobre os niveis condicionantes gerais de modo a viabilizar mudança no nível 1. Esta avaliação vai depender do tipo de mudança almejada, da intensidade da mesma e do tipo de problema escolhido (da 1.o). A localização dos nós críticos vai depender do anterior.

\section{2 - A definição dos projetos preliminares}

Esta etapa consiste na definição de todos os projetos que a priori podem levar a Si até o cumprimento da l.o. É uma etapa de definição preliminar já que os projetos ainda não foram submetidos às analises de factibilidade, de coerência e de viabilidade.

Os projetos preliminares têm uma delimitação temporal mais ou menos clara, no sentido de que apontam para o cumprimento ou para a construção de situações intermediárias ( $\mathrm{S} 1, \mathrm{~S} 2, \mathrm{~S} 3 \ldots$...) e de que se inter-relacionarão em uma seqüência temporal definida para conduzir progressivamente à $\mathbf{l} .0$ (desdobramento da 1.0 em situações parciais).

Os projetos representam, neste entendimento, momentos parciais da estratégia maior que os engloba (verda. deiros processos ou momentos tático-conjunturais de 1 arco direcional e estratégico global).

A definição destes projetos se origina, como se viu, da comparação entre a 1.0 ou situação intermediária e á Si (de base). $O$ primeiro momento está representado pela identifi. cação no diagnóstico de base dos problemas que se opõem ao logro da situação-objetivo (final ou intermediária) e na seleção prioritária deles. $O$ segundo consiste na determinação das prováveis soluções, dos meios ou das alternativas necessários ao equacionamento dos problemas tendo como referencial o cumprimento da situação-objetivo e na sua priorização (tendo em vista que um mesmo problema admite várias soluções prováveis).

Os critérios de priorização são simultaneamente técnicos e políticos, com destaque para estes últimos, conside- 
rando-se o grau de agregação específico da formulação de políticas (macro). Os parâmetros de priorização e escolha das soluções preliminares são:

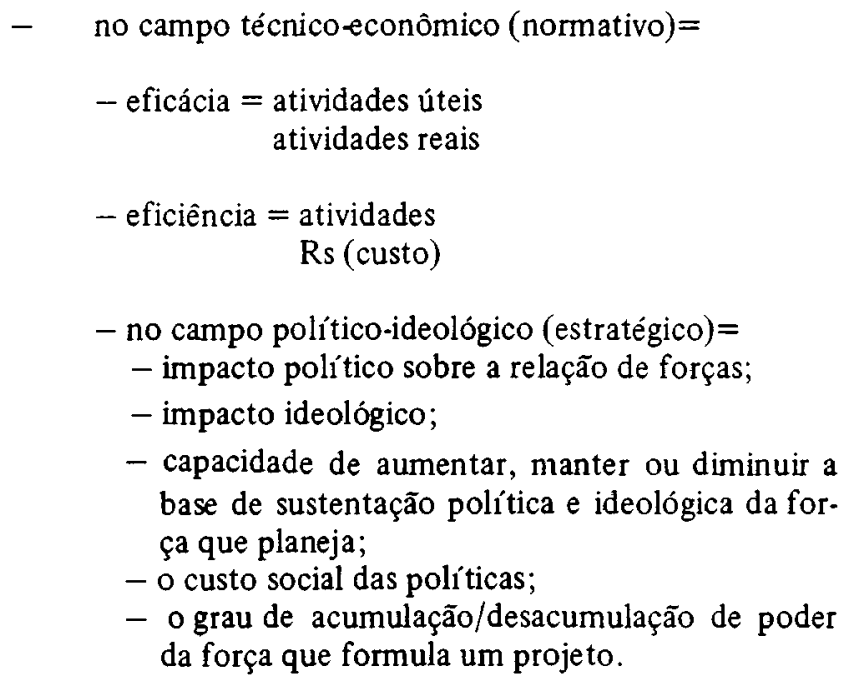

Neste último nivel, o diagnóstico estratégico provê subsídios riquíssimos na medida em que enseja a previsão dos efeitos políticos, em termos de capacidade de produção de fatos, de poder, que um projeto tem em relação aos insumos ou recursos de poder que emprega (medida de eficiência política).

Não se pode esquecer, todavia, que o critério mais importante para a seleção dos meios ou das alternativas é a ca. pacidade de provocar a mudança necessária ao alcance da I.o (consistência da trajetória com a I.o). Em grande parte, a consistência da trajetória com a situação-objetivo depende, como se viu, da correta identificação dos nós críticos que aparecem na explicação situacional, da seleção dos processos explicativos com maior sensibilidade para provocar uma mudança na direção desejada.

\section{3. - Análise de factibilidade dos projetos preliminares}

Definidos os projetos preliminares é necessário sub. metê-los à análise de factibilidade que consiste em responder às seguintes perguntas.

- há disponibilidade de recursos para implementar esses projetos?

- há disponibilidade de tecnologia e de insumos técnico-científicos (incluindo conhecimentos) para realizar tais projetos? 
- a estrutura administrativa e gerencial existente apresenta condições de implementação de tais projetos ou será necessário promover uma (macro) adequação de tal estrutura?

Caso as respostas sejam afirmativas, estará assegurada a factibilidade e o processo de desenho contínuo. Caso contrário, será necessário revisar os projetos, a própria situação. objetivo (feed-back) ou será indispensável a criação de factibilidade para eles, em termos dinâmicos (factibilização).

Aparentemente a factibilidade é um problema técnico; no entanto, como a questão dos Rs é um problema tam. bém político não se pode separar a factibilidade da viabilidade (a não ser em termos formais).

\section{4 - Análise da coerência dos projetos preliminares}

Consiste esta análise, na avaliação do grau de consistência ou de compatibilidade interna dos diferentes projetos (ou conteúdos internos de um mesmo projeto) que fazem parte de um mesmo programa geral de atuação e na consistência, já mencionada, entre os projetos e a situação-objetjvo.

O objetivo da análise de coerência interna é o de eliminar proposições inconsistentes com o conjunto setorial, aumentando a compatibilidade e procurando aumentar a sinergia (somação de efeitos). Consiste na eliminação das incoerências invalidantes do conjunto. Ex.: de duas diretrizes inconsistentes em política econômica - aumentar o emprego e reduzir o déficit público, cortando despesas (uma terá que ser abandonada ou negligenciada, o que implica numa opção política, que tem a ver com a I.o hegemônica).

A análise de coerência externa é a avaliação da compatibilidade existente entre a formulação setorial e a formulação global. Ex.: política de expansão e fortalecimento do setor público em saúde vis-à-vis a adoção de um modelo de capitalismo liberal, privatizador na economia. Esta situação configura uma incoerência externa que condiciona a viabilidade (inseparabilidade de etapas).

Em geral, a formulação setorial tem um peso menor em termos de determinação e de viabilidade (capacidade de gerar viabilidade) do que a formulação maior, o que sugere que a formulação setorial deveria obedecer em geral a uma proposta global de âmbito societário, de modo a assegurarse a coerência externa e a viabilidade (representatividade e singularidade da l.o setorial).

Caso os projetos consigam responder positivamente à questão da coerência, o que implica na realização de revi- 
sões visando aumentar a compatibilidade, o conjunto de projetos de caráter agora menos preliminar deverá passar pela análise de viabilidade.

O conjunto de projetos, garantida a factibilidade e a coerência, corresponde a um programa direcional ou ao arco direcional que mede a situação-objetivo à inicial (conjunto de projetos que tem realmente a capacidade de mudar na direção da 1.o).

Falta ainda definir como esse programa direcional acontecerá em termos de trajetória ou sequiencia e de intensidade (magnitude da colocação do (s) projeto (s), grau de orquestração, de mobilização publicitária, etc.). A definição da trajetória real corresponde ao desenho estratégico, à definição dos arcos conjunturais ou dos caminhos parciais reais, dos rodeios que se farão necessários, etc. A formulação do desenho estratégico depende da análise de viabilida. de.

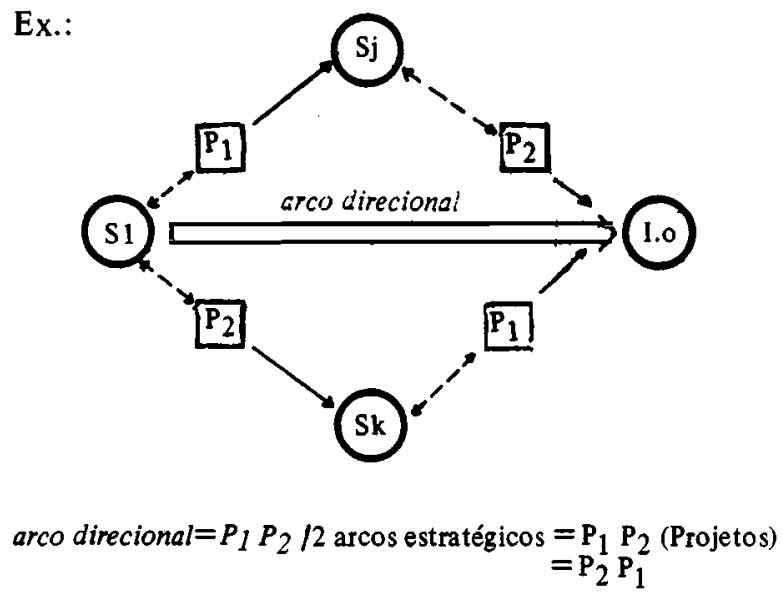

Antes de entrar na análise de viabilidade (que tem por objetivo escolher o arco estratégico mais viável), vale a pena tentar uma ilustração do processo de definição de projetos preliminares em saúde, no contexto da Reforma Sanitária. A Reforma é a palavra de ordem que expressa semioticamente uma estratégia ou melhor um programa direcional, (de atuação), tendo em vista o cumprimento da I.o do S.U.S. (Sistema Unificado de Saúde). Esse programa direcional está constituido de vários projetos, cuja identificação rigorosa se torna necessário para avaliar sua factibilidade, coerência a viabilidade e para formular sua estratégia. Estes projetos seriam: 
- projeto de reformulação administrativa ou de integração administrativa (Ministério Único da Reforma Sanitária; Conselhos Estaduais e Municipais de Saúde, etc.).

- projeto de integração financeira (criação de Fundos Únicos de Saúde a todos os níveis administrativos; repasse de Rs financeiros intensificando a experiência das A.I.S.)

- projeto de integração de serviços de saúde, baseado na distritalização ou criação de sistemas locais de saú. de;

- projeto de recursos humanos (formaçáo; reciclagem; ajustamento de cargos e salários: isonomia salarial, etc.)

- projeto de informatização e de montagem de sistemas únicos de planejamento visando a programação integrada (podendo caber no projeto de integração de serviços ou no projeto administrativo).

- proj. de intensificação e canalização da participação popular em saúde (podendo se diluir nos outros porque permeia todos eles), etc.

Todos estes projetos interagem dinamicamente entre si e se articulam em uma seqüência temporal, que deve ser determinada em função da questão da viabilidade, (coerên. cia e factibilidade). $O$ projeto de integração financeira re. presentou (pois o processo está em marcha) o marco inicial do desenho adquirido pelo processo, com as A.I.S. A seqüência seguinte está por ser articulada (ou será articulada pela realidade). Os projetos envolvem zonas de maior ou menor conflito, por conta de sua factibilidade e viabilidade e envolvem questões de coerência externa. Exs.: a factibilidade (e viabilidade portanto) da isonomia salarial (muito conflito); a viabilidade da unificação ministerial (conflitos com a burocracia estatal); a descentralização e o fortalecimento do consórcio municipal e a reforma tributária (questão de coerência externa e de viabilidade)...

\section{5 - A análise de viabilidade do programa direcional e o desenho estratégico}

A análise de viabilidade consiste na avaliação da possibilidade política dos projetos. Supõe o levantamento dos graus de apoio, rejeição ou indiferença que as políticas provocam nos diferentes atores sociais e políticos e na capacidade desses atores de poder atuar (capacidade de produção de fatos) no sentido de viabilizar seus projetos. Tem como objetivo o desenho estratégico. 
Os elementos de uma análise de viabilidade são:

- a determinação dos atores que atuam no cenário político (em saúde) e de seus respectivos projetos societários;

- a definição dos projetos setoriais (I.o) que estes atores impulsionam com maior representatividade;

- a definição do (s) grau (s) de interesse que os vários projetos suscitam nos diferentes atores;

- a definição do vetor de peso dos atores ou da capacidade de promoção de projetos;

- a simulação da viabilidade dinâmica no horizonte temporal;

O ponto de partida está representado pela definição dos atores e de seus projetos, ou pela definição dos projetos mais representativos em pauta (na conjuntura). Esses projetos gerarão um diferencial de reaçōes sociais de apoio, in diferença e rejeição; essa variedade reacional deverá ser precisada mediante a aplicação de matrizes de interesse (grau de). ${ }^{7}$

Ex.: matriz de interesses

\begin{tabular}{|c|c|c|c|}
\hline Interesses & \multicolumn{3}{|c|}{ Brojetos } \\
\cline { 2 - 4 } Forças Soc. & $\mathbf{P}_{\mathbf{1}}$ & $\mathbf{P}_{\mathbf{2}}$ & $\mathbf{P}_{\mathbf{3}}$ \\
\hline $\mathrm{F}_{\mathbf{1}}$ & $+0,8$ & +1 & $+0,8$ \\
\hline $\mathrm{F}_{2}$ & $-0,5$ & -1 & $-0,7$ \\
\hline
\end{tabular}

A matriz de interesses permite distinguir as relações de propósito (apoio, indiferença e rejeição) ou relações de intenção e caracterizar os graus de conflito que se configuram em torno dos objetivos embutidos nos projetos. Por ex. em relação à $\mathrm{P}_{2}$, conflito máximo.

$A$ análise do vetor de peso, por outro lado, corresponde à análise da força, capacidade ou do peso político ${ }^{7}$ capaz de mobilizar ou de gerar cada força social em relação aos projetos. É a análise das relações de poder que condicionam definitivamente a viabilidade dos projetos (e dos conflitos respectivos). $O$ vetor de peso está constituido de vários elementos como por ex.: o grau de adesão popular, (A1) o no de parlamentares (A2), o controle de agências de poder (A3), o controle dos meios de publicidade ou comunicação, (A4) etc. Portanto, a avaliaçã̃o de tal setor implica na seleção prévia de tais elementos que variam (de importância) em função dos projetos. De maneira que o vetor de peso depende dos projetos especificos em pauta, variando em função daqueles. Poder-se-ia afirmar; então,que um ponto importante na avaliação da capacidade de prođução de 
fatos (projetos) consiste na determinação das relações intrumentais entre projetos e poder (que passa pela delimitação dos elementos de vetor de peso que mais pesam na análise).

A necessidade de objetivar o valor de peso surge como uma obrigação colocada por aqueles casos que implicam em conflitos ao nível dos interesses ou relações de intenção, no sentido de podermos saber a mais provável forma de resolução (estratégia) de tal conflito. A objetivação poderá ser realizada com uma matriz como a seguinte (em que os projetos pertencem a uma forma social $\mathrm{x}$ no caso $F_{1}$ ).

\begin{tabular}{|c|c|c|c|c|c|}
\hline \multicolumn{2}{|c|}{ Forças sociais } & P1 & P2 & P3 & $\begin{array}{l}\text { Valor geral } \\
\text { elementos }\end{array}$ \\
\hline $\mathrm{F} 1$ & $\begin{array}{l}\text { a } 11 \\
\text { a } 12 \\
\text { a } 13\end{array}$ & $\begin{array}{l}X 111 \\
X 121 \\
X 131\end{array}$ & $\begin{array}{l}X 112 \\
X 122 \\
X 132\end{array}$ & $\begin{array}{l}X 113 \\
X 123 \\
X 133\end{array}$ & $\begin{array}{l}\text { a } 11 \\
\text { a } 12 \\
\text { a } 13\end{array}$ \\
\hline F2 & $\begin{array}{l}\text { a } 21 \\
\text { a } 22 \\
\text { a } 23\end{array}$ & $\begin{array}{l}\times 211 \\
\times 221 \\
\times 221\end{array}$ & $\begin{array}{l}X 212 \\
\times 222 \\
\times 232\end{array}$ & $\begin{array}{l}X 213 \\
\times 223 \\
X 233\end{array}$ & $\begin{array}{l}\text { a } 21 \\
\text { a } 22 \\
\text { a } 23\end{array}$ \\
\hline valor elemento & vetor $F 1$ & X 11 & $\times \quad 12$ & X 13 & $\overline{\mathrm{X}} 1$ \\
\hline valor elemento & vetor $\mathrm{F} 2$ & X 21 & $\times 22$ & X 23 & $\times \overline{2}$ \\
\hline
\end{tabular}

A comparação do vetor de peso de cada força social em relação a cada projeto nos dá um indicativo da viabilidade:

$\mathrm{F} 1$ (X 111 i X 121 i X 131) ><F2 (X 211; X 221; $X$ 231) Se $F 1$ (X 11)< F2 (X 21) tem evidentemente um grau de interesse positivo e intenso em P 1, P1 é viável (até prova em contrário).

A sistemática da análise de viabilidade consiste em definir previamente todas as trajetórias possiveis (sequêencias específicas de projetos) e em aplicar seguidamente tal forma de. cálculo estratégico a essas trajetórias, para se definir a mais provável em termos de viabilidade. Esta análise é portanto seqüencial, por etapas, cobrindo toda a brecha histórica.

A definição prévia das trajetórias possiveis supōe portanto considerar as relações de precedência funcional entre os projetos (precedência técnica e política), isto é, supõe definir aqueles projetos que se constituem necessariamente em requisitos técnicos e políticos para a implementação dos outros (anteriormente de alguns projetos). Feita essa caracterização das traje tórias possiveis, ensaia-se então. $o$ cálculo da viabilidade.

$\mathrm{O}$ aspecto da simulação dinâmica da viabilidade se refere principalmente à necessidade de se prever o impacto 
sobre o vetor de peso em S 2 que um projeto aplicado em Si irá ter, ou seja, ao impacto sucessivo dos projetos sobre as situações futuras em termos dos graus de in teresse e do (s) vetor (es) de peso das forças sociais. Essa análise é cada vez mais incerta à medida que se avança na análise de viabilidade de situações de futuro mais distante (o que não nos exime de tal cálculo probabilístico).

A formulação do desenho estratégico começa, como se viu, pela seleção de trajetórias iniciais de acordo com a precedência. $\mathrm{Na}$ análise da precedência é importante caracterizar aqueles projetos que representam elementos estratégicos capazes de potencializar o cumprimento dos restantes. Em geral esses elementos ou projetos estratégicos são mais conflitivos e deveriam ser desencadeados inicialmente ou com uma certa anterioridade (o grau de anterioridade também está relacionado com a provável viabilidade conjuntural desses projetos conflitivos que em geral é maior no inicio de quaisquer administração legitimada minimamente).

No exemplo da Reforma Sanitária a reformulação administrativa (criação de instâncias administrativas de in tegração) e a política especifica de RHs podem representar passos estratégicos prévios à plena in tegração dos serviços sanitários.

A formulação definitiva do desenho estratégico resul. ta da definição da "anterioridade" estratégica funcional e do cálculo da viabilidade das seqüências.

$\mathrm{Se}$ as sequências possiveis são $\mathrm{P} 1, \mathrm{P} 2, \mathrm{P} 3 / \mathrm{P} 2, \mathrm{P} 1, \mathrm{P} 3 /$ $\mathrm{P} 3, \mathrm{P} 2, \mathrm{P} 1$ o cálculo de viabilidade consistente na análise das relações de intenção e das relações de poder (vetor) nas três situações $S 1, S 2, S 3$ determinará a mais provável que poderá ser, por ex.: P1, P2, P3 quando F1 (x) $>$ F2 (X) nas três situações respectivas (se essa trajetória é inviável em $\mathrm{P} 1$ o início deverá ser ensaiado por P2 ou P3).

A questão da análise de viabilidade não pode ser encarada, porém, de maneira estática. Se por ex.: Pl é inviável e P1 é considerado estratégico pela força social que o apóia, tal força deverá identificar a forma (estratégica) capaz de viabilizar dinamicamente P1. Tal forma equivale ao lançamento de projetos táticos processuais ou de criação especí. fica de viabilidade dos projetos estratégicos (ex. P1).

É importante salientar que o desenho estratégico envolve a questāo da sequienciação temporal assim como da in. tensidade no lançamento. Todavia, contemplaria aqueles passos táticos-precessuais de viabilização ou potencialização do desenho.

Diante da impossibilidade de se obter viabilidade para um arco direcional determinado, a força social interessada deverá aceitar a possibilidade de revisar sua I.o e seu programa direcional (retroalimentação). 
Devemos assinalar, ainda, que o processo de análise de viabilidade é mais fácil quando se refere a um conjunto de projetos correspondente a uma força social X. Entretanto, como as várias forças sociais formulam 1.0 diferentes e portanto vários programas direcionais a análise de viabilidade deverá trabalhar com um elenco ou malha de probabilidades maior, o que dificulta o cálculo, mas não o torna impossível, (simulação do entrechoque de imagens e programas).

A questão do desenho estratégico da Reforma Sanitária no Brasil merece alguns.comentários finais. Insinuamos anteriormente que, em termos de seqüência, $a$ intensificação da política de integração financeira (patrocinada pelas AIS) representa um projeto anterior ou inicial de tal estratégia. Formulamos, por outro lado, que a realização dos projetos de integração administrativa real e de padronização e promoção dos recursos humanos setoriais poderão representar fatores condicionantes ou determinantes na realização efetiva do projeto de integração de serviços. A construção da trajetória definitiva depende da análise de viabilidade. Alguns aspectos dessa viabilidade se referem à coerência externa. As dificuldades observadas em relação à viabilidade da integração administrativa e ao nivel dos RHs (problemas de factibilidade financeira inclusive) e à viabilidade da descentralização efetiva, com o fortalecimento do (s) nivel (is) municipal e estadual, poderão encontrar uma solução positiva no interior de processos mais amplos tais como a Reforma Administrativa e Financeira (e especialmente aqui a questão de Reforma Tributária). A inseparabilidade do setorial e do global nos remete obrigatoriamente a encarar a questão da viabilidade setorial da Reforma Sanitária como um problema político de maior alcance que tem a ver com o destino do projeto de democratização, especialmente no que diz respeito às possibilidades de aprofundamento do social, a partir da realização de reformas de estrutura. Isto é uma questão, no entanto, de legitimidade social.

\section{4. - COMENTÁRIOS FINAIS}

A planificação estratégica é uma possibilidade metodológica que deve ser explorada porque é necessária. É necessária porque como afirma Carlos Matus toda ação deve ser precedida de um cálculo, cálculo esse que transcen. de a visão normativa. Agora, a planificação estratégica é, antes de mais nada, uma questão de raciocínio, de raciocinio estratégico, válido inclusive no campo da vida prática. $O$ problema da viabilidade e a necessidade de uma estratégia são elementos inerentes à construção do futuro humano, futuro incerto, pois que é criativo e imaginativo. A simulação hu- 
mana do futuro baseada na análise da conduta criativa é um campo inexplorado de múltiplas possibilidades, uma verdadeira arte de jogadores que utilizam o poder da consciência humana (e da propria intuição criadora) para firmar seus pontos de vista, seus projetos no universo da contradição e o conflito.

Mas, o planejamento é um instrumento que atua basicamente sobre o presente, sobre a conjuntura. A análise do futuro é importante quando referenciada a um tipo de atuação tática no presente imediato, na vida imediata. Futuro e presente fazem parte do mesmo ato de construção do destitino dos seres humanos. A planificação estratégica é, nesse entendimento, uma planificação eminentemente conjuntural, atrelada à conjuntura, em que o desenho global da estratégia vital, é o pano de fundo dos passos que se empreen. dem hoje e não ontem ou depois.

$\mathrm{O}$ grande mérito do enfoque estratégico consiste em ter denunciado aquela visão da planificação que entende a si própria como uma relação entre um ator e um sistema controlável (dialética do "eu e do sistema") e em ter afirmado uma nova dialética, o "eu e o outro", com a base relacional que caracteriza o surgimento do enfoque estratégico.

A planificação é por conseguinte uma relação de ou entre pessoas. É um enfrentamento de vontades sociais ou a confluência de vários vetores sociais, da qual resulta um único vetor real, fruto da história. A principal função da planificação consiste em captar tal vetor social e em ajudar a sua construção.

This paper analyses, first, the strategical planning logic compared with the economical and technocratical approach, historically displaced.

The author proceeds to discuss a model of devising health policies based on the Carlos Matus strategical planning approach and the Pan American Health Planning Center's devising model (CPPS, 1975).

\section{BIBLIUGRAFIA/NOIAS}

1. MATLS. Carlos: Estratégia y Plan Siglo XXI, Médico 1978, cap. II

2. MalUUS, Carlos: Politica y Plan 2? lidición. Publicaciones de INVLRPLAN. Ínezucla 1982. cap. II.

3. OPAS/CPPS. Formulación de Politicas de Salud 1975. cap. 111.

4. MA ГUS, Carlo E. Estratégia y Plan. cap. III.

5. MATUS, Carlos. Politica y Plan. cup. 3 Planificación de Situachones FC C México 1983.

6. TISTA, Mário. Ia Planificación Estratégica en el setor salud.

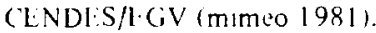

7. Matus, Carlos. Política y Plan cap. 5.

Cadernos de Saúde Pública, R.J., 413): 444-462, out/dez, 1987. 